\title{
A brief history of the development of mannequin simulators for clinical education and training
}

\author{
J B Cooper, V R Taqueti
}

Qual Saf Health Care 2004;13(Suppl 1):i11-i18. doi: 10.1136/qshc.2004.009886

Simulation for medical and healthcare applications, although still in a relatively nascent stage of development, already has a history that can inform the process of further research and dissemination. The development of mannequin simulators used for education, training, and research is reviewed, tracing the motivations, evolution to commercial availability, and efforts toward assessment of efficacy of those for teaching cardiopulmonary resuscitation, cardiology skills, anaesthesia clinical skills, and crisis management. A brief overview of procedural simulators and part-task trainers is also presented, contrasting the two domains and suggesting that a thorough history of the 20+ types of simulator technologies would provide a useful overview and perspective. There has been relatively little cross fertilisation of ideas and methods between the two simulator domains. Enhanced interaction between investigators and integration of simulation technologies would be beneficial for the dissemination of the concepts and their applications.

See end of article for authors' affiliations

Correspondence to: Dr Jeffrey B Cooper, Department of Anesthesia and Critical Care, Massachusetts General Hospital, 55 Fruit Street CLN 250, Boston, MA 02114, USA; jcooper@ partners.org
W hile still in a relatively nascent stage of development, simulation for healthcare applications has already evolved through its initial historical phases. * Recounting stories of some key simulation technologies could be useful for informing future simulation advocates. In this brief history of medical simulation we focus primarily on the origin of mannequin simulators, especially those employing computer control, and we examine some of the pedagogy and evaluations of effectiveness that aided dissemination. A listing of part-task trainers for surgical and medical procedures (which we refer to as "procedural" simulators) and more limited discussion of their origins are also given to indicate the extent of activity in that area.

\section{DEFINITIONS}

Some definitions are needed for this discussion. As there is no accepted convention, those used here are arbitrary, although drawn from suggestions by others. "Simulator" refers to a physical object or representation of the full or part task to be replicated. "Simulation" refers to applications of simulators for education or training. The term simulator is used by some specifically to refer to technologies that recreate the full environment in which one or more targeted tasks are carried out. This can also be called fully immersive simulation. The term "part-task trainer" should be applied to technologies that replicate only a portion of a complete process or system. However, simulator is commonly used in a generic sense to apply to all technologies that are used to imitate tasks. Gaba defines 11 spectra of simulation characteristics. ${ }^{4}$ One spectrum uses the following terms:

- verbal (role playing)

- standardised patients (actors)

- part-task trainers (physical; virtual reality)

- computer patient (computer screen; screen based "virtual world")

- electronic patient (replica of clinical site; mannequin based; full virtual reality)

While most of these types of simulations and simulators are not examined in this history, all will probably be integrated into the restructuring of the education and training processes for clinicians in all domains. That most simulation technologies and techniques for medical and healthcare applications are not examined here is a reflection of how broad the field is already. Even for the areas that are covered, the discussions are relatively brief summaries, describing only key events that can be uncovered.

\section{APPROACH}

We searched PubMed for the keywords "simulation" and "simulator" for the years 1965 to 2004. Several summary publications were used as primary sources to other references. Because a substantial body of work was conducted by private corporations, we used several non-referenced sources, including hand searches of many volumes of the proceedings of Medicine Meets Virtual Reality. Many other sources of abstractsfor example, other medical and nursing meetings-were not searched because of time and

Abbreviations: ACRM, Anesthesia Crisis Resource Management; ASC, Anesthesia Simulator-Consultant; CASE, Comprehensive Anesthesia Simulation Environment; CPR, cardiopulmonary resuscitation; CRM, crew resource management; $E R C P$, endoscopic resection of colonic polyps; GAS, Gainesville Anesthesia Simulator

*Good and Gravenstein refer to the very early roots of simulation, for instance to the medieval quintain, a mounted figure used for lance practice by horse mounted knights. ${ }^{.}$There is a successful history of simulation in nonmedical domains, with aviation most often cited as the example to emulate. That experience has influenced the development of medical simulators, but is described elsewhere. $^{23}$ 
resource constraints. Interviews were conducted with several pioneering investigators and developers of technology for procedural simulators.

\section{ORIGINS OF THE MODERN ERA OF SIMULATION}

We begin with the earliest published accounts of some part task trainers that are precursors to computer based simulators. Gaba ${ }^{5}$ has produced a detailed history of the development of mannequins and some screen simulators, particularly as they were first used in anaesthesia, and he and his colleagues also reported on a 10 year experience in using simulation for crisis resource management training. ${ }^{6}$ Issenberg et al presented an overview of simulators and trainers in several domains. ${ }^{7}$

\section{Resusci ${ }^{\circledR}$-Anne to SimMan ${ }^{\circledR}$}

While not computer driven and having relatively limited functionality, Resusci-Anne marks a beginning for discussion because it is widely used for medical training and is a progenitor of one of the two current commercial mannequin simulators. Created in the early 1960s, this mannequin for training in mouth to mouth ventilation was designed by Asmund Laerdal, a successful Norwegian manufacturer of plastic toys (fig 1). ${ }^{8} \mathrm{He}$ was encouraged to do so by Dr Bjorn Lind and other Norwegian anaesthesiologists, following $\mathrm{Dr}$ Peter Safar's revelations about the superiority of mouth to mouth resuscitation. ${ }^{9}{ }^{10}$ The airway could be obstructed, and it was necessary to use hyperextension of the neck and forward thrust of the chin to open the airway before initiating insufflation of air into the mannequin by the mouth to mouth technique that Safar had described. Based on evidence of the efficacy of closed chest massage, ${ }^{11}{ }^{12}$ Safar later advised Laerdal to include an internal spring attached to the chest wall, which permitted simulation of cardiac compression. The possibility of training for the ABC (airway, breathing, circulation) of cardiopulmonary resuscitation (CPR) on the simulator was thus born. ${ }^{13}$ This early simulator of a dying victim, not breathing and lacking a heart beat, became known as Resusci-Anne and has been widely used for CPR training. ${ }^{14}$

The Laerdal company did not develop a higher fidelity mannequin until the mid-1990s when encouraged to do so by

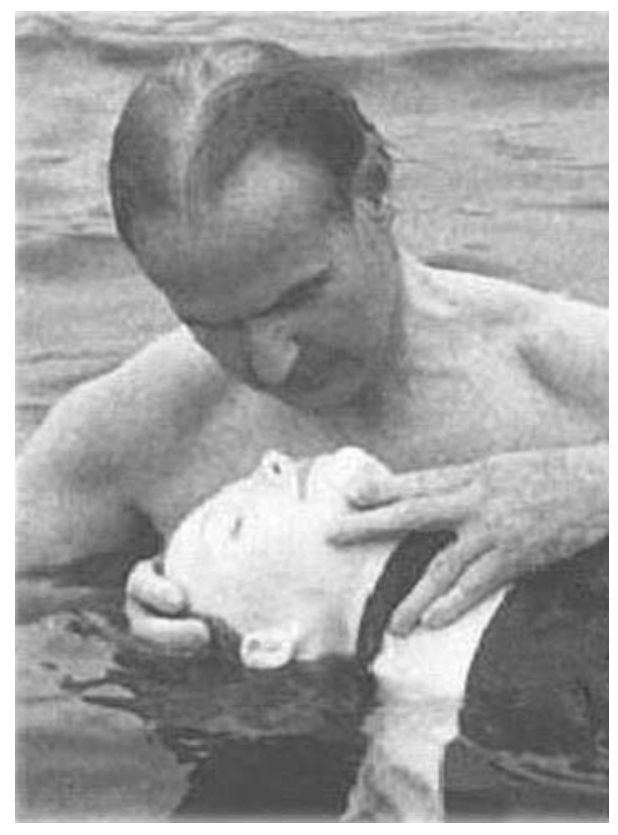

Figure 1 Asmund Laerdal with Resusci-Anne, in about 1970. many, including Dr Ake Grenvik, a Safar colleague at the University of Pittsburgh. Drs Rene Gonzales and John Schaefer, also of the University of Pittsburgh, developed a more anatomically correct airway and simulator, which was manufactured by Medical Plastics Corporation (MPL) of Texas. ${ }^{15}$ Laerdal acquired MPL and developed the simulator, then called SimMan, which was substantially cheaper than other available higher fidelity mannequin simulators, thus altering the market in a fashion described by the disruptive innovation model of Christensen. ${ }^{16}$

\section{Sim One}

Sim One is a starting point for true computer controlled, mannequin simulators, particularly for simulation of the entire patient (fig 2). ${ }^{17-19}$ Conceived by Dr Stephen Abrahamson, an engineer, and Dr Judson Denson, a physician, at the University of Southern California in the mid-1960s, it was built in collaboration with Sierra Engineering and Aerojet General Corporation. Abrahamson, in a video acceptance of an award from the Society for Technology in Anesthesia, described the idea as originating from Aerojet's need to develop peacetime applications of its capabilities in the face of diminishing military funding, before the escalation of the Vietnam conflict. The initial concept of replicating anaesthesia machine functions quickly evolved to the objective of recreating more of the entire patient. After meeting with rejection from the National Institutes of Health and military funding sources, the project to build a prototype was supported by a three year, $\$ 272000$ grant from the US Office of Education.

The simulator was a remarkably lifelike mannequin, controlled by a hybrid digital (with "4096 words of memory") and analogue computer. It had many high fidelity features: the chest was anatomically shaped and moved with breathing, the eyes blinked, the pupils dilated and constricted and the jaw opened and closed. To a limited extent, it was used for training and to conduct some primitive experiments about efficacy. While not rigorously justified by the methods, the authors claimed that the simulator had a "twofold" advantage in training anaesthesia residents in the skill of endotracheal intubation while "posing significantly less threat to patient safety."20

Sim One did not achieve acceptance. Only one was constructed; sadly, nothing remains of it. The computer technology was too expensive for commercialisation. But, equally importantly, the market for training in other than an apprenticeship model was non-existent. Gaba speculates that the vision for the use of Sim One was too narrow to create



Figure 2 Dr Stephen Abrahamson (seated) and Dr Judson Denson with Sim One in the late 1960s. 
sufficient demand. ${ }^{19}$ These pioneers were too far ahead of the technology and the demand for its application.

\section{Harvey cardiology mannequin}

Harvey is a full sized mannequin that simulates 27 cardiac conditions. It is the earliest example of the modern concept of a part-task trainer for medical skills training. It was first demonstrated in 1968 at the American Heart Association Scientific Sessions by Dr Michael Gordon of the University of Miami Medical School under the title of a Cardiology Patient Simulator (fig 3). ${ }^{21}{ }^{22}$ The motivation behind Harvey can be traced to Gordon's days as a cardiac fellow under his mentor, Dr W Proctor Harvey of Georgetown University, after whom the mannequin was named. Inspired by Dr Harvey's use of audiovisuals in his teaching, Gordon built a comprehensive cardiology patient simulator in collaboration with the Center for Research in Medical Education (CRME). ${ }^{23}$

The simulator displays various physical findings, including blood pressure by auscultation, bilateral jugular venous pulse wave forms and arterial pulses, precordial impulses, and auscultatory events in the four classic areas; these are synchronised with the pulse and vary with respiration. Harvey is capable of simulating a spectrum of cardiac disease by varying blood pressure, breathing, pulses, normal heart sounds, and murmurs.

Harvey has undergone fairly rigorous testing for educational efficacy, perhaps more than any other simulation technology. Pilot studies documenting Harvey's effectiveness in teaching bedside cardiological examination skills were first reported in 1980..$^{22}$ In 1987, a study of the use of Harvey among 208 senior medical students in five medical schools was sponsored by the National Heart, Lung, and Blood Institute. ${ }^{24}$ Fourth year medical students who trained with Harvey during their cardiology elective performed significantly better than their peers who interacted only with patients. This was assessed through skills post-tests using the simulator as well as patients. There were no reported differences in the way patients perceived the professional behaviour of Harvey trained versus non-Harvey trained students. Rather, students who were better able to interpret findings on Harvey showed enhanced confidence and ability to interpret those same findings on patients at the bedside. ${ }^{24} 25$

Harvey has been used for training medical and nursing students, interns, and residents, and for continuing education of family physicians..$^{22-28}$ It has also been applied to

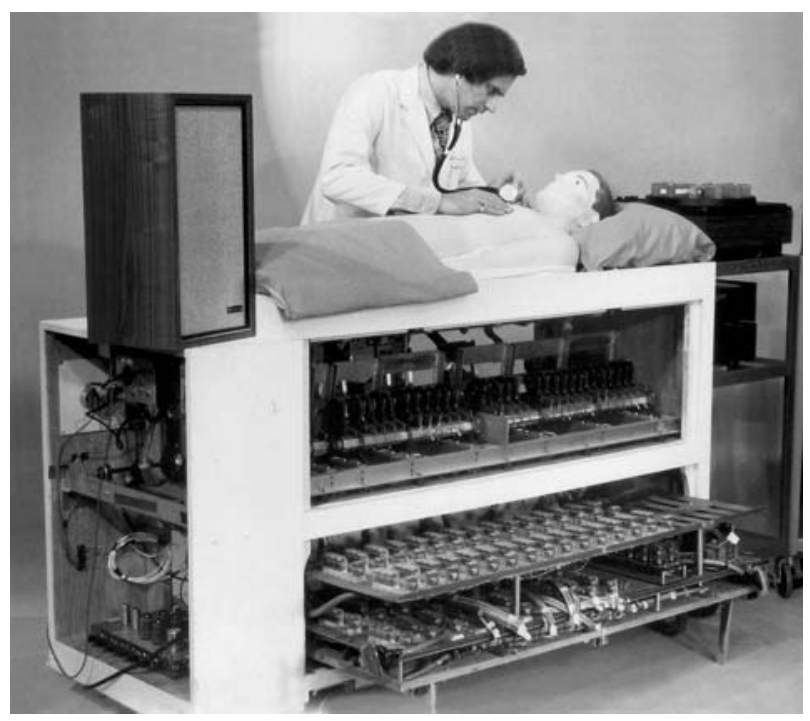

Figure 3 Michael Gordon with Harvey in the early 1970s. testing bedside cardiovascular examination skills of medical students, residents, and attending physicians in internal medicine, paediatrics, and emergency settings. ${ }^{24}{ }^{29-31}$ By providing a platform for standardised testing, Harvey was early in allowing for more comprehensive sampling of different skills.

As it matured, Harvey was equipped with a curriculum of cardiovascular conditions, with associated learning goals and data-rich slide programmes developed by a national consortium of physicians and educators. ${ }^{22}$ It is frequently used in conjunction with the UMedic multimedia computer curriculum, comprising 10 patient centred, cased based programmes, which provides a comprehensive generalist curriculum in cardiology. ${ }^{32}$

Around the time in which testing with Harvey was gaining momentum, a separate heart sound simulator was shown to improve cardiac auscultation skills of nurses. ${ }^{33}$ Harvey also inspired the development of smaller, more portable cardiology patient simulators, for example, Simulator K.. ${ }^{34}$

\section{Physiological models for realistic simulation}

An important contribution to the history of realistic mannequin simulators was the development of mathematical models of the physiology and pharmacology of drugs in anaesthesia. These served a dual function: they evolved into screen based simulators for different applications and also provided the underlying concepts in modelling physiology that were needed to support hands-on simulators with automatic control. Several computer based simulations of various aspects of anaesthesia have been developed. Philip created a program for teaching uptake and distribution of anaesthetic agents, which he called GasMan ${ }^{\circledR} \cdot{ }^{35}$ Sikorski et al described a computer based simulation for instructing anaesthesia residents in managing intraoperative events. ${ }^{36}$

More complete models of human physiology have enabled higher fidelity, more realistic simulations. Building on the work of others in physiological modelling, Dr N T Smith and colleagues at the University of California San Diego (UCSD) conceived a multicompartment model of human physiology and pharmacology that formed the basis for SLEEPER, a screen based simulator. ${ }^{37-39}$ Intended primarily to teach physiology and pharmacology, it was a fairly complex system requiring more computing power than was then available in desktop computers. SLEEPER evolved into a broader application, BODY ${ }^{\mathrm{TM}}$, which was marketed first by Marquette Medical Systems and currently by Advanced Simulation Corporation.

Dr Howard Schwid, a former fellow in the UCSD labs, further developed the concept of screen based simulation by simplifying the models to run on a desktop computer and thus reach a wider audience. ${ }^{40}$ Schwid and O'Donnell also expanded the application to include critical event management, for which there was a greater market ${ }^{41}{ }^{42}$; this was commercialised in a product called the Anesthesia Simulator Recorder, marketed in 1989. These workers built an expert system around the anaesthesia simulator to provide learning objectives, management advice, and an automated debriefer. The new program was named Anesthesia Simulator Consultant (ASC). The basic product has further evolved into a family of screen based simulators marketed by Anesoft Corporation. Schwid and others conducted numerous experiments to assess the utility of ASC, including studies of efficacy of learning advanced cardiac life support skills, and comparison of screen based and mannequin simulation learning. ${ }^{43-46}$

\section{Realistic mannequin simulators}

Independently, and for different objectives, two mannequin simulators were developed at approximately the same time at opposite ends of the USA. Both were partly inspired by efforts 
to improve patient safety under anaesthesia-a movement that had been inspired by research into error and human factors in anaesthesia and by the formation of the Anesthesia Patient Safety Foundation, which funded simulation research and development in the late 1980s. ${ }^{47-49}$ The pedagogies for employing these simulators have evolved into widely used tools for skills and behaviour training in many domains.

At the Stanford Medical School affiliated Veterans' Affairs Palo Alto Health Care System, Dr David Gaba and colleagues fabricated what is probably the first prototype of a mannequin simulator developed for investigating human performance in anaesthesia. A pre-prototype is shown in fig 4. The original version, used for experiments and training in early 1987, was numbered CASE 1.2 (Comprehensive Anesthesia Simulation Environment). ${ }^{50}$ It combined commercially available waveform generators and virtual instruments-for example, a non-invasive blood pressure monitor-on a Macintosh Plus computer, with a commercially available mannequin to create a "patient" whose vital signs could be manipulated to simulate critical events. Placed in a real operating room and surrounded by actual equipment, this was the beginning of the high realism, physical simulation environment. The next version, CASE 2.0, contained a model of cardiovascular physiology running on a Transputer (a microprocessor chip designed for parallel processing with other such chips), making it partially model driven (as opposed to CASE 1.2) and also an example of parallel processing. ${ }^{51}$

The CASE system and its progeny were used by its developers at Stanford and subsequently by others to investigate various aspects of human performance in anaesthesia and related domains. ${ }^{52-55}$ From those experiments, in which critical events were created and the response of subjects observed and measured, emerged a division of performance assessment into technical and behavioural skills. ${ }^{55}$ A training curriculum, Anesthesia Crisis Resource Management (ACRM), based on the then relatively new aviation model of crew resource management (CRM) was also developed, evaluated, and propagated. ${ }^{56}{ }^{57}$ ACRM teaches generic responses to critical events and incorporates debriefings that use videotapes of simulation scenarios. Course evaluations suggested that the realism was sufficient to elicit realistic behaviours. ${ }^{56} 58$ In 1992, the CASE 2.0 system was transported to Boston, where a series of sessions was conducted to test the feasibility of transferring the educational model. ${ }^{59}$ Anaesthesia faculty, residents, and nurse anaesthetists in the hospitals affiliated with Harvard Medical School were engaged in a 10 week trial. Success there led to the establishment of a collaborative educational centre dedicated to simulation based training-the Boston

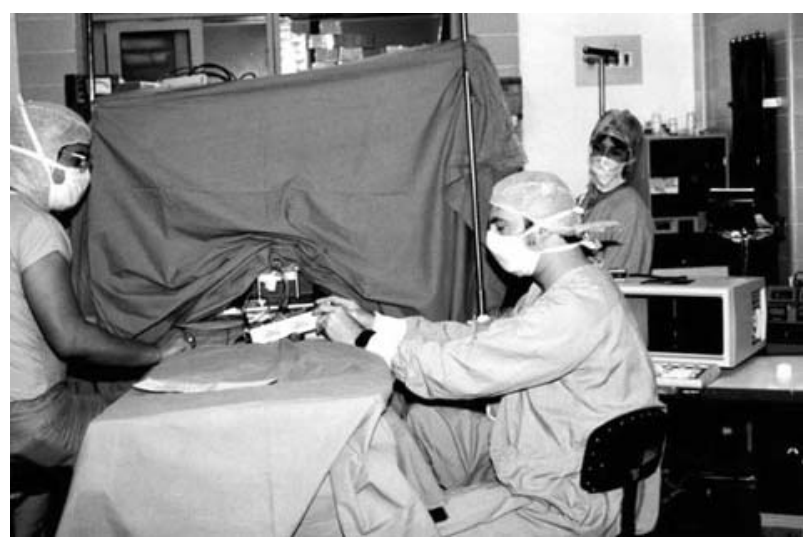

Figure 4 Dr David Gaba with earliest CASE pre-prototype, May 1986.
Anesthesia Simulation Center (later renamed to the Center for Medical Simulation) - which was probably the first adopter of the technology for education applications outside the centres that developed the different technologies.

The CASE system and ASC software models were licensed to CAE-Link (a descendent of the original Link Aeronautical Corporation that produced the pioneering "Link Trainer", the first significant simulator in aviation)" for commercialisation. ${ }^{60}$ The CAE patient simulator used modified physiological models from the ASC models, with large sets of patient characteristics, including cardiovascular and respiratory function, acid-base balance, and pharmacokinetics and pharmacodynamics representing numerous disease states. The mannequin had many features, including airway anatomy that could be altered to mimic degrees of difficulty of intubation, palpable carotid and radial pulses, lungs that simulated behaviour during spontaneous and controlled ventilation, heart and breath sounds, eyes that opened and closed, and a thumb twitch, as used for monitoring neuromuscular blockade during anaesthesia. The system was driven by a Sun SPARC 1 computer, which allowed for automatic responses to drug interventions entered by the operator and for manual manipulation of physiological variables.

The company transmuted several times (from CAE-Link to CAE Medical Electronics, to Eagle of Binghamton, New York), and the product was eventually sold to Medsim Ltd, headquartered in Israel. Medsim, which previously had developed and marketed a part-task trainer for ultrasound training (UltraSim ${ }^{\mathrm{TM}}$ ) eventually abandoned patient simulation, in part because its marketing strategy to create training centres did not fit the demand of the times.

At around the same time that CASE 1.2 was being born, a multidisciplinary team at the University of Florida, Gainesville, led by Dr Michael Good and mentored by Dr J S Gravenstein, developed the Gainesville Anesthesia Simulator (GAS). ${ }^{61}$ It arose from an interest in training anaesthesia residents in basic clinical skills. The project began with the capability for diagnosis of faults in anaesthesia machines, in which controllable mechanical failure modes were embedded. Attaching a lung simulator to the machine extended the training challenge. This was developed into a complete mannequin, aimed primarily toward diagnosis of single source critical events in anaesthesia. The mannequin had a sophisticated lung model, which mimicked uptake and distribution of anaesthetic gases. Later versions incorporated a system for automatically recognising drugs as they were injected. In contrast to the more instructor driven manual operation of CASE 1.2, this software enabled sequences of physiological changes both predefined and in response to actions of the trainer and trainee.

GAS was subjected to an important early test of efficacy, reported only in an abstract. ${ }^{62}$ Sixteen anaesthesia residents were randomised into two cohorts: with and without simulation instruction. Clinical evaluations-in which evaluators were blinded to the subject cohort status-indicated a more rapid learning curve for the simulation trained group, although both groups achieved the same level of proficiency at the end of the three month trial. The trial was ended primarily because of resident demand to participate in simulation training.

GAS was licensed to Loral Data Systems Inc, which later spun off the simulator product to a new company, Medical Education Technologies Inc (Sarasota, Florida). The METI product was dubbed the Human Patient Simulator ${ }^{\mathrm{TM}}$ (HPS). A paediatric version, Pediasim ${ }^{\mathrm{TM}}$, and a simpler and more portable model, the ECS ${ }^{\mathrm{TM}}$, were introduced in the late $1990 \mathrm{~s}$ and early 2000s, respectively. 


\section{Other mannequin simulators}

Several other mannequin simulators were constructed and used in the assessment of training processes but without becoming commercial products. Chopra et al developed the Leiden Anesthesia Simulator as a tool for teaching critical event management in anaesthesia. ${ }^{63}$ It appears to have been modelled on CASE 1.2 and was used in an experiment to assess the efficacy of simulation based training to improve skills in critical event management. ${ }^{64}$ The Sophus Anaesthesia Simulator was developed in 1991 by a team from the Department of Anaesthesiology at Herlev Hospital, Roskilde University and Risø National Laboratory in Denmark. ${ }^{65}$ Schaefer and colleagues in Basel employed a combination of the Sophus simulator and part-task surgical skills trainer using a perfused pig liver to teach Team Oriented Management Skills (TOMS), developed independently from, but in a similar way to, crisis resource management. ${ }^{66}{ }^{67}$ The combined simulator system was called Wilhelm Tell. ACCESS (Anaesthesia Computer Controlled Emergency Situation Simulator) was developed in the United Kingdom as a part-task trainer for anaesthesia skills. ${ }^{68}$

\section{VALIDATION AND ASSESSMENT}

Some educators believe that the acceptance of simulation based training will not occur until there is substantial validation of its efficacy and effectiveness in cost-effectively improving learning or patient outcomes. In the realm of mannequin simulation, there have been validation studies demonstrating the interest and enthusiasm of students, high levels of realism, and construct and content validity. 56 586466 69-71 $^{6}$ There has been only limited assessment of the transfer of training to the real environment and no assessment of effectiveness in reducing risk or improving patient outcomes. ${ }^{62}{ }^{72}$ Important efforts to develop the measurement instruments and rating scales needed to assess performance and behavioural change in simulated or real environments have been described..$^{55} 70$ Such measures are required for the validation that may be needed for broader acceptance, although few such measures of outcome improvement-for example, reduction in accidents-are available for simulation in non-medical domains. Gaba has noted many obstacles to obtaining definitive proof of the impact of simulation, including the need to study long term applications of the technology and curricula rather than one shot applications. ${ }^{70} \mathrm{He}$ further has observed that "no industry in which human lives depend on the skilled performance of responsible operators has waited for unequivocal proof of the benefits of simulation before embracing it." ${ }^{\prime 74}$

\section{DISSEMINATION OF THE MANNEQUIN SIMULATION CONCEPT}

Examination of the publications and discussions with some of the developers suggest that the groups involved in the early phases of the simulators described above were almost entirely independent. The development of CASE was not informed by the models of Schwid or Smith. GAS and CASE developed entirely independently of each other and neither relied on lessons from Sim One (Gravenstein J S, Gaba D M, personal communications). None of the anaesthesia simulators seems to have been informed by the history of development or dissemination of either Harvey or Resusci-Anne. ResusciAnne on the other hand, appears to have evolved into SimMan as a result of the developing market for mannequin simulators that was stimulated by METI's and Medsim's patient simulators.

Once the more recent simulators took their initial form, interactions between the various developers occurred at least in part as a result of conferences focusing on simulator and simulation research. The earliest conferences were organised by the FDA and the Anesthesia Patient Safety Foundation in 1988 and 1989..$^{75}$ A broader conference, "Simulators in Anesthesiology Education", was held at the University of Rochester (New York) in 1995. In 1998, the Society for Technology in Anesthesia and what was then called The Rochester Simulator Symposium jointly sponsored a meeting. The following year, the first international meeting on medical simulation was held. The Society in Europe for Simulation Applied to Medicine (SESAM) was formed in 1994. More recently, the Society for Medical Simulation (SMS) was organised. The meeting named "Medicine Meets Virtual Reality", first held in 1991, has been a focus of interactions primarily for virtual reality and procedural simulation, although some mannequin simulation work has been presented there. "The International Conference on Medical Image Computing and Computer-Assisted Intervention", a merger of three technical and scientific meetings, was first held in 1998 and is a venue for presentation of scientific and technical concepts underpinning simulation. All of these meetings have probably facilitated dissemination and cross fertilisation of the early conceptual developments. However, there has been relatively little overlap of topics and investigators between the various conferences.

\section{BRIEF COMMENTS ON PROCEDURAL SIMULATION}

Although the field of procedural simulation is also still in early stages of growth and the technology penetration is minimal, there are already many computer based part-task trainers for a spectrum of surgical and interventional tasks. $^{73}{ }^{77}$ We have identified over 20 types of skills training devices that have been described in published reports, many of which are in various stages of development or marketing (table 1 gives a list of early references to each type). At the time of writing, there has been no comprehensive review of this component of the medical simulation field. Publication of the early developments appeared at about the same time as the early developments in mannequin simulators, perhaps the earliest report being in 1987 by Gillies and Williams for fibre-endoscopic training. ${ }^{78 *}$ Baillie et al described a computer simulation for teaching basic ERCP techniques in $1988 .^{79} \mathrm{~A}$ trainer for catheter insertion developed by HT Medical, formerly Hightechsplanations, was one of the earliest practical devices to be developed, although literature citations did not appear until later $^{88}$ (Meglan D, Foster Miller Corporation, personal communication). Satava has written about some of the early simulators for laparoscopic surgery. ${ }^{77}$ Key funding of surgical simulation was catalysed substantially by funding from the Defense Advanced Research Projects Agency (DARPA).

Studies of transfer of training of skills to patient care for procedural skills trainers could be a pivotal historical point in the broader adoption of simulation concepts for all forms of simulation. Taffinder et al demonstrated the validity of the MIST VR ${ }^{\mathrm{TM}}$ (Minimally Invasive Surgical Trainer Virtual Reality) simulator in differentiating experienced from novice surgeons. ${ }^{101}$ Also using MIST VR, Seymour et al showed that basic skills improved performance of residents in laparoscopic cholecystectomy ${ }^{102}$ There have also been some studies demonstrating that surgical skills training devices can be used to assess proficiency in psychomotor skills. ${ }^{103}$

Given the large number of procedural simulators and trainers developed for different medical domains, the history of how each was spawned and evolved is likely to be rich in interesting stories. The contrasts and similarities of evolution

*As the original sources of many procedural trainers were from corporate research and development versus the generally academic source of most mannequin simulators, publications are less indicative of the chronology of development or appearance of specific technologies. 
Table 1 Listing of types of simulator by earliest identified date of reference



between procedural, mannequin, and other simulation modes could be informative of how innovation is catalysed, evolves, and diffuses in healthcare education and training.

\section{DISCUSSION}

The history of mannequin simulators suggests that the early years were marked by several parallel, almost entirely independent developments that pursued somewhat different objectives and led to differences in technical approach. Resusci-Anne was developed specifically for practice in a specific skill, CPR. Harvey was born out of a desire to teach skills in cardiac diagnosis more effectively. CASE and CRM were motivated by an interest in safety and especially in the study of human performance. GAS, also from a patient safety perspective, was primarily intended to teach basic clinical skills and diagnosis in anaesthesia. Essentially all of the original simulators and simulations have evolved into products or concepts that are currently enabling changes in healthcare education and improvements in patient safety. Future prospects are good for simulation, simulators, and part-task trainers to have a strong, positive impact on healthcare, especially by lowering the risk to patients of training, by providing a method of learning about care processes, and by helping to establish a strong culture of teamwork and collaboration within the clinical workforce.

This review of the literature of both mannequin and procedural simulation suggests that there is relatively little overlap of source material references between the major domains. While there are clear differences in applications, technologies, and approach, there are many similarities in pedagogy and methods for validation and dissemination. That there is so little cross fertilisation between the various simulation camps may suggest gaps in collaboration that could be hampering broader discovery, innovation, and dissemination. That is further evidenced by the existence of different professional meetings for mannequin and procedural simulators and perhaps even a lack of appreciation of the potential synergy between the various simulation modes. There have been some examples of the value of integration of procedural and mannequin simulators for team training. ${ }^{66} 104$
Key messages

- The modern era of mannequin simulators developed from several different roots and for different applications.

- There are now at least 20 different types of task trainers for medical procedures available or in development.

- There has not yet been much cross fertilisation between the academic developers of the procedural and mannequin simulator technologies.

- Integration of procedural and mannequin technologies is needed to enable full team training to achieve the broadest potential of simulation.

- Becoming broadly familiar with the technologies, pedagogies, and research methods in each domain within the field will serve to better inform strategies and tactics for application and diffusion of simulation into healthcare education, training, and research.

This concept should be extended to enable full team training for all varieties of clinical teams.

Simulation in healthcare education and training appears to be gaining acceptance, but it has not yet reached what would be called a "tipping point" ${ }^{105}$ of widespread adoption. There is still relatively low penetration of the entire market of medical and healthcare education. While many are in use, they are still the exception, not the rule, for healthcare education and training. Technical developments may be limiting, but the greater limitation derives from the model for reimbursement for healthcare and education in industrialised countries. The lack of research showing effectiveness, transfer of training to the clinical environment, and cost-effectiveness are also barriers to diffusion of the technology.

It is not yet certain that the next historical phase of simulation will achieve the acceptance and dramatic growth that are needed to lead a radical change in healthcare education and contribute substantially to patient safety. Collaboration and greater interdisciplinary research across simulation domains than has yet occurred could be synergistic and leverage the efforts of all. We suggest that everyone working in the field become broadly familiar with the technologies, pedagogies, and research methods in each domain to better inform strategies and tactics for application and diffusion of simulation into healthcare education, training, and research.

\section{Authors' affiliations}

J B Cooper, Department of Anesthesia, Harvard Medical School, Massachusetts General Hospital, Boston, Massachusetts, USA

V R Taqueti, Harvard-MIT Division of Health Sciences and Technology

\section{REFERENCES}

1 Good M, Gravenstein J. Anesthesia simulators and training devices. Int Anesth Clin 1989;27:161-6.

2 Page R. Brief history of flight simulation, 103 David Rd, Lucas Heights, NSW 2234, Australia.

3 Moore K. Electronic flight simulation. Available at http:// www.bleep.demon.co.uk/SimHist9.html (last accessed 16 March 2004).

4 Gaba DM. The future vision of simulation in healthcare. Qual Saf Healthcare 2004; 13(Suppl 1):i2-10.

5 Gaba DM. Simulators in anesthesiology. Adv Anesth 1997;14:55-94.

6 Gaba DM, Howard SK, Fish K, et al. Simulation-based training in anesthesia crisis resource management (ACRM): a decade of experience. Simulation Gaming 2001;32:175-93.

7 Issenberg S, McGaghie W, Hart I, et al. Simulation technology for health care professional skills training and assessment. JAMA 1999:282:861-6.

8 Grenvik A, Schaefer JJ. From Resusci-Anne to Sim Man: the evolution of simulators in medicine. Crit Care Med 2004;32:556-557. 
9 Safar P, Escarraga L, Elam J. A comparison of the mouth-to-mouth and mouth-to-airway methods of artificial respiration with the chest-pressure armlift methods. N Engl J Med 1958;258:671-7.

10 Safar P. Ventilatory efficacy of mouth-to-mouth artificial respiration. Airway obstruction during manual and mouth-to-mouth artificial respiration. JAMA 1958;167:335-41.

11 Kouwenhoven WB, Jude JR, Knickerbocker GG. Closed-chest cardiac massage. JAMA 1960;173:1064-7.

12 Jude JR, Kouwenhoven WB, Knickerbocker GG. Cardiac arrest: report of application of external cardiac massage on 118 patients. JAMA 1961;178:1063-71.

13 Safar P, Brown TC, Holtey WH, et al. Ventilation and circulation with closed chest cardiac massage in man. JAMA 1961;176:574-6.

14 Winchell SW, Safar P. Teaching and testing lay and paramedical personnel in cardiopulmonary resuscitation. Anesth Analg 1966;45:441-9.

15 Schaefer J, Gonzalez R. Dynamic simulation: a new tool for difficult airway training of professional healthcare providers. Am J Clin Anesth 2000;27:232-42.

16 Christensen CM. The innovator's dilemma. Boston: Harvard Business School, 1997.

17 Denson J, Abrahamson S. A computer-controlled patient simulator. JAMA 1969;208:504-8.

18 Carter D. Man-made man: anaesthesiological medical human simulator. J Assoc Adv Med Instrum 1969;3:80-6.

19 Abrahamson S. Human simulation for training in anesthesiology. In: Ray CD. Medical engineering. Chicago: Yearbook, 1974:370-4.

20 Abrahamson S, Denson J, Wolf R. Effectiveness of a simulator in training anesthesiology residents. J Med Educ 1969;44:515-19.

21 Gordon MS. Cardiology patient simulator: development of an automated manikin to teach cardiovascular disease. Am J Cardiol 1974;34:350-5.

22 Gordon MS, Ewy GA, Felner JM, et al. Teaching bedside cardiologic examination skills using "Harvey," the cardiology patient simulator. Med Clin North Am 1980;64:305-13.

23 http://crme.med.miami.edu/harvey_about.html (last accessed 5 July 2004)

24 Ewy GA, Felner JM, Juul D, et al. Test of a cardiology patient simulator with students in fourth-year electives. J Med Educ 1987;62:738-43.

25 JO, Calhoun JG, Tenhaken JD, et al. Harvey: the impact of a cardiovascular teaching simulator on student skill acquisition. Med Teach 1987;9:53-7.

26 Gordon MS, Ewy GA, Felner JM, et al. A cardiology patient simulator for continuing education of family physicians. J Fam Pract 1981;13:353-6.

27 Karnath B, Thornton W, Frye AW. Teaching and testing physical examination skills without the use of patients. Acad Med 2002;77:753.

28 Sajid AW, Ewy GA, Felner JM, et al. Cardiology patient simulator and computer-assisted instruction technologies in bedside teaching. Med Educ 1990;24:512-17.

29 St. Clair EW, Oddone EZ, Waugh RA, et al. Assessing housestaff diagnostic skills using a cardiology patient simulator. Ann Intern Med 1992;117:751-6.

30 Jones JS, Hunt SJ, Carlson SA, et al. Assessing bedside cardiologic examination skills using "Harvey," a cardiology patient simulator. Acad Emerg Med 1997:4:980-5.

31 Gaskin PR, Owens SE, Talner NS, et al. Clinical auscultation skills in pediatric residents. Pediatrics 2000; 105:1184-7.

32 Issenberg SB, Gordon MS, Gordon DL, et al. Simulation and new learning technologies. Med Teach $2001 ; 23: 16-23$.

33 Champagne MT, Harrell JS, Friedman BJ. Use of a heart sound simulator in teaching cardiac auscultation. Focus Crit Care 1989;16:448-56.

34 Takashina T, Shimizu M, Katayama H. A new cardiology patient simulator Cardiology 1997;88:408-13.

35 Philip J. Gas Man - an example of goal oriented computer-assisted teaching which results in learning. Int J Clin Monit Comput 1986;3:165-73.

36 Sikorski J, Jebson P, Hauser P. Computer-aided instruction simulating intraoperative events in anesthesia residents training [abstract]. Anesthesiology 1983;59:A470.

37 Fukui Y, Smith NT. Interaction among ventilation, the circulation, and the uptake and distribution of halothane. Use of a hybrid computer. Model I. The basic model. Anesthesiology 1981;54:107-18.

38 Fukui Y, Smith NT. Interaction among ventilation, the circulation, and the uptake and distribution of halothane. Use of a hybrid computer. Model II. Spontaneous vs. controlled ventilation, and the effects of $\mathrm{CO}_{2}$ Anesthesiology 1981;54:119-24.

39 Smith NT, Sebald AV, Wakeland C, et al. Cockpit simulation: will it be used for training in anesthesia? Rockville MD, Anesthesia Simulator Curriculum Conference, September 1989: SLEEPER, pp 1-9).

$40 \mathrm{Schwid} \mathbf{H}$. A flight simulator for general anesthesia training. Comput Biomed Res 1987;20:64-75

41 Schwid HA, O'Donnell D. The anesthesia simulator-recorder: a device to train and evaluate anesthesiologists' responses to critical incidents. Anesthesiology 1990;72:191-7.

42 Schwid H, O'Donnell D. Anesthesiologists' management of simulated critical incidents. Anesthesiology 1992;76:495-501.

43 Schwid HA, O'Donnell D. The anesthesia simulator-consultant: simulation plus expert system. Anesthesiology Review 1993;20:185-9.

44 Schwid HA, Rooke GA PM, Ross BK. Screen-based anesthesia simulation with debriefing improves performance in a mannequin-based anesthesia simulator. Teach Learn Med 2001;13:92-6.

45 Nyssen AS, Larbuisson R, Janssens $M$, et al. A comparison of the training value of two types of anesthesia simulators: computer screen-based and mannequin-based simulators. Anesth Analges 2002;94:1560-5.

46 Schwid HA, Rooke GA, Ross BK, et al. Use of a computerized advanced cardiac life support simulator improves retention of advanced cardiac life support guidelines better than a textbook review. Crit Care Med 1999;27:821-4

47 Cooper JB, Newbower RS, Long CD, et al. Preventable anesthesia mishaps a human factors study. Anesthesiology 1978;49:399-406.

48 Anesthesia Patient Safety Foundation. www.apsf.org (last accessed 19 March 2004)

49 Cooper JB. APSF grants support key safety research. J Clin Monit 1997:13:59-65.

50 Gaba DM, DeAnda A. A comprehensive anesthesia simulator environment: re-creating the operating room for research and training. Anesthesiology 1988;69:387-94.

51 Gaba DM, Williams J. CASE simulation system status report 9/89. Anesthesia Simulator Curriculum Conference. Rockville, Maryland, September 1989: CASE, pp 1-4).

52 Gaba DM, DeAnda A. The response of anesthesia trainees to simulated critical incidents. Anesth Analg 1989;68:444-51.

53 Gaba DM, Lee T. Measuring the workload of the anesthesiologist. Anesth Analg 1990;71:354-61.

54 Howard SK, Gaba DM, Rosekind MR, et al. The risks and implications of excessive daytime sleepiness in resident physicians. Acad Med 2002;77:1019-25.

55 Gaba DM, Howard SK, Flanagan B, et al. Assessment of clinical performance during simulated crises using both technical and behavioral ratings. Anesthesiology 1998;89:8-18.

56 Howard SK, Gaba DM, Fish K, et al. Anesthesia crisis resource management training: teaching anesthesiologists to handle critical incidents. Aviat Space Environ Med 1992:63:763-70.

57 Gaba DM, Fish K, Howard SK. Crisis management in anesthesiology. Edinburgh: Churchill Livingstone, 1994.

58 Holzman R, Cooper JB, Gaba DM, et al. Anesthesia crisis resource management: real-life simulation training in operating room crisis. $J$ Clin Anesth 1995;7:675-87.

59 Cooper JB. Patient safety and biomedical engineering. In: This is No Humbug!: reminiscences of the Department of Anesthesia at the Massachusetts General Hospital, ed Kitz RJ, Boston:Department of Anesthesia and Critical Care, Massachusetts General Hospital, 2002:377-420.

60 CAE-Link. http://www.invent.org/hall_of_fame/ 130 induction linktrain.asp (last accessed 4 July 2004).

61 Good $M$, Lampotang S, Gibby G, et al. Critical events simulation for training in anesthesiology. J Clin Monit Comput 1988;4:140.

62 Good M, Gravenstein J, Mahla M, et al. Can simulation accelerate the learning of basic anesthesia skills by beginning residents? [abstract]. Anesthesiology 1992;77:A1133.

63 Chopra V, Engbers FHM, Geerts MJ, et al. The Leiden anaesthesia simulator. $\mathrm{Br} J$ Anaesth 1994;73:287-92.

64 Chopra V, Gesnink B, DeJong J, et al. Does training on an anaesthesia simulator lead to improvement in performance? $\mathrm{Br} J$ Anaesth 1994;73:293-7.

65 Christensen UJ, Andersen SF, Jacoben J, et al. The Sophus anaesthesia simulator V.2.0. Int J Clin Monit Comput 1994;14:11-16.

66 Helmreich $\mathbf{R}$, Schaefer $\mathrm{H}$. Team performance in the operating room. In: Bogner $M$, eds. Human error in medicine. Hillsdale, NJ: Lawrence Erlbaum, 1994:225-53.

67 Marsch S. Team oriented medical simulation. In: Henson L, Lee A, eds. Simulators in anesthesiology education. New York: Plenum, 1998:51-5.

68 Byrne A, Hilton P, Lunn J. Basic simulations for anaesthetists: a pilot study of the ACCESS system. Anaesthesia 1994;49:376-81.

69 Devitt J, Kurrek M, Cohen M, et al. Testing internal consistency and construct validity during evaluation of performance in a patient simulator. Anesth Analg 1998;86:1160-4.

70 Devitt J, Kurrek $M$, Cohen $M$, et al. The validity of performance assessments using simulation. Anesthesiology 2001;95:36-42.

71 Sica G, Barron D, Blum R, et al. Computerized realistic simulation: a teaching module for crisis management in radiology. Am J Roentgenol 1999;172:301-4

72 Blum R, Cooper JB, Feinstein $D$, et al. Crisis resource management training for anesthesia faculty: A new approach to continuing faculty education. Med Ed 2004;38:45-55.

73 Jha AK, Duncan BW, Bates DW. Simulator based training and patient safety in making health care safer: a critical analysis of patient safety practices. Agency for Healthcare Research and Quality, US Dept of Health and Human Services, 20 July, 2001:511-18.

74 Gaba DM. Improving anesthesiologists' performance by simulating reality [editorial]. Anesthesiology 1992;76:491-4.

75 Gravenstein JS. Anesthesia simulators featured at meeting. APSF Newsletter 1989;4:8.

76 Mellone IC. Simulation takes Washington by Storm. APSF Newsletter 1989:4:46-7.

77 Satava $R$, Jones $S$. The future is now: virtual reality technologies. In: Tekian A, McGuire C, McGaghie W, eds. Innovative simulations for assessing professional competence: from paper and pencil to virtual reality. Chicago: University of Illinois, 1999:179-93.

78 Gillies DF, Williams CB. An interactive graphic simulator for the teaching of fibrendoscopic techniques. In: Marechal G, eds. EUROGRAPHICS 1987 Amsterdam: North Holland, 1987:127-38.

79 Baillie J, Gillies D F, Cotton PB, et al. Computer simulation for basic ERCP training: a working model [abstract]. Gastrointest Endosc 1988;35:177a.

80 Williams CB, Haritsis A, Burger P, et al. An interactive computer simulator for teaching colonoscopy [abstract]. Gastrointest Endosc 1990;36:220a. 
81 Satava RM. Virtual reality surgical simulator. The first steps. Surg Endosc 1993;7:203-5.

82 Munro A, Park KG, Atkinson D, et al. A laparoscopic surgical simulator. $J$ R Coll Surg Edinb 1994;39:176-7.

83 Wallwiener D, Rimbach S, Bastert G. The HysteroTrainer, a simulator for diagnostic and operative hysteroscopy. J Am Assoc Gynecol Laparosc 1994;2:61-3.

84 Smeak DD, Hill LN, Beck ML, et al. Evaluation of an autotutorial-simulator program for instruction of hollow organ closure. Vet Surg 1994;23:519-28.

85 O'Toole RV, Jaramaz B, DiGioia AM, et al. Biomechanics for preoperative planning and surgical simulations in orthopaedics. Comput Biol Med 1995;25:183-91.

86 Rouland JF, Dubois P, Chaillou C, et al. SOPHOCLE (Ophthalmologic Simulator of Laser Photocoagulation): contribution to virtual reality. J Fr Ophtalmol 1995; 18:536-41.

87 Sinclair MJ, Peifer JW, Haleblian R, et al. Computer-simulated eye surgery. A novel teaching method for residents and practitioners. Ophthalmology 1995; 102:517-21.

88 Merril GL, Barker VL. Virtual reality debuts in the teaching laboratory in nursing. J Intraven Nurs 1996;19:182-7.

89 Kuppersmith RB, Johnston R, Jones SB, et al. Virtual reality surgical simulation and otolaryngology. Arch Otolaryngol Head Neck Surg 1996; 122:1297-8

90 MS, Middlebrook A, Sutton C, et al. MIST VR: a virtual reality trainer for laparoscopic surgery assesses performance. Ann R Coll Surg Engl 1997;79:403-4.

91 Chong CK, How TV, Black RA, et al. Development of a simulator for endovascular repair of abdominal aortic aneurysms. Ann Biomed Eng 1998;26:798-802.

92 Hahn JK, Kaufman R, Winick $A B$, et al. Training environment for inferior vena caval filter placement. Stud Health Technol Inform 1998;50:291-7.

93 Tuggy ML. Virtual reality flexible sigmoidoscopy simulator training: Impact on resident performance. J Am Board Fam Pract 1998;11:426-33.
94 Smith S, Wan A, Taffinder N, et al. Early experience and validation work with Procedicus VA - the Prosolvia virtual reality shoulder arthroscopy trainer. Stud Health Technol Inform 1999;62:337-43.

95 O'Toole RV, Playter RR, Krummel TM, et al. Measuring and developing suturing technique with a virtual reality surgical simulator. J Am Coll Surg 1999; 189:114-27.

96 Vahora F, Temkin B, Marcy W, et al. Virtual reality and women's health: a breast biopsy system. Stud Health Technol Inform 1999;62:367-72.

97 Ballaro A, Briggs T, Garcia-Montes F, et al. A computer generated interactive transurethral prostatic resection simulator. J Urol 1999; 162:1633-5

98 Dawson SL, Cotin S, Meglan D, et al. Designing a computer-based simulator for interventional cardiology training. Catheter Cardiovasc Interv 2000;51:522-7.

99 Colt HG, Crawford SW, Galbraith O. Virtual reality bronchoscopy simulation: a revolution in procedural training. Chest $2001 ; 120: 1333-9$.

100 Bloom MB, Rawn CL, Salzberg AD, et al. Virtual reality applied to procedural testing: the next era. Ann Surg 2003;237:442-8.

101 Taffinder $\mathbf{N}$, et al. Validation of virtual reality to teach and assess psychomotor skills in laparoscopic surgery: results from randomized controlled studies using the MIST VR laparoscopic simulator. Stud Health Technol Inform 1998;50:124-30.

102 Seymour N, Gallagher A, Roman S, et al. Virtual reality training improves operating room performance. Ann Surg 2002;236:458-64.

103 Gallagher A, Richie KB, McClure N, et al. Objective psychomotor skills assessment of experienced, junior, and novice laparoscopists with virtual reality. World J Surg 2001;25:1478-83.

104 Walzer TB, Gardner R, Raemer DB. Obstetrical emergency - an apparatus to simulate shoulder dystocia. Albuquerque: Proceeding International Meeting on Medical Simulation, 2004.

105 Gladwell M. The tipping point: how little things can make big differences. Boston: Little Brown, 2000. 


\section{NOTICES}

Healthcare: Is Europe Getting Better? 20th January 2005, Renaissance Hotel, Brussels.

For more information, please visit: www.Europeanvoice.com.

\section{0th European Forum on Quality Improvement in Health Care}

13th to the 15th April 2005, ExCel Conference Centre, London, UK.

To request a brochure or submit an abstract, please visit: http://www.quality.bmjpg.com.

\section{Postgraduate Certificate in Evidence Based Health Care}

20th September 2004 to the 30th September 2005, University of Oxford Department for Continuing Education, UK.

The Certificate is intended for health professionals who wish to obtain the skills that are needed to access existing evidence, disseminate evidence, and use evidence to promote informed decision making. The programme seeks to accommodate the busy and demanding work schedules of healthcare professionals and, therefore, is provided on a part-time basis. The Programme also offers flexibility in allowing candidates to choose empirical topics for study which are relevant to their professional needs and interests besides providing a core body of knowledge, skills and expertise in evidence-based health care thus allowing a progression from learning how to use evidence-based health care to how to establish it.

For further information or to receive application details contact: Health Sciences
Portfolio, University of Oxford Department for Continuing Education; tel: +44 (0) 1865 286941; email: cpdhealth@conted.ox.ac.uk; http://www.conted.ox.ac.uk.

\section{Managing Change in Health Care}

10th to the 14th January and 4th to the 8th April 2005, University of Oxford Department for Continuing Education, UK.

This 10 day course uses a combination of action learning and work based learning to teach principles of change management to health professionals. Four key steps to change management are used to resolve work based healthcare issues and contribute to clinical effectiveness programmes: conducting organisational analysis; working with multidisciplinary teams to identify appropriate strategies for change in your workplace; implementing plans for health care improvement; developing feasible methods for monitoring change; and overall evaluation of the process. The course provides:

- Flexible learning for professionals with limited time

- Ongoing tutor support for a work based project

- Transferable skills and materials applicable to varied change management projects

For further information or to receive application details contact: Health Sciences Portfolio, University of Oxford Department for Continuing Education; tel: +44 (0) 1865 286941; email: cpdhealth@conted.ox.ac.uk; http://www.conted.ox.ac.uk.

\section{Process Improvement Courses}

Until end of March 2005, George Mason University.
For further information or to receive application details please go to: http://cqi. gmu.edu

\section{CORRECTIONS}

doi: 10.1136/qshc.2004.009886.corr l

In supplement 1 this year, October 2004, the paper by J B Cooper and V R Taqueti (A brief history of the development of mannequin simulators for clinical education and training. Qual Saf Health Care 2004;13:il1-il8) was missing an acknowledgement, which follows: The authors thank Drs Richard Satava, Steve Dawson, Dwight Meglan, and John Schaefer for providing historical information and insights for this article.

In the quality improvement report by Muller et al (BMJ 2004;328:934-8; reprinted in QSHC 2004;13:444-449) a misunderstanding during editing led to an error in reporting the authors' methods. In the third paragraph of the section "Strategy for change", the correct text should read, "We provided [not obtained] feedback twice during routine staff meetings" and "We presented [not determined] the proportion of patients who had received allogenic or autologous blood transfusion after total joint replacement". Technology led to a further slip, this time at proof stage. At the end of the fourth paragraph of the section "Effects of change", a confusion caused by "track changes" resulted in the misrepresentation of an increase in units of transfused blood. The correct increase in units of transfused blood in Zurich should be from 52700 to 60600 $(+15 \%)$ [not plus/minus $15 \%$ ]. 